\title{
Evaluation of sphincter-preserving surgery for rectal cancer
}

\author{
Ahmed Gaber Mahmoud, $M D^{1}$; Ayman M. A. Ali, $M D^{1}$; \\ Wael Barakaat Ahmed, $M S^{1}$; Ahmed R.H. Ahmed, Ph.D., MD'; \\ Abd El-Hafez Hosny, MD ${ }^{1}$
}

\author{
1) General Surgery Department, Sohag University, Egypt. \\ 2) Pathology Department, Sohag University, Egypt.
}

Background: Rectal carcinoma constitutes a health problem, previously managed with abdomino-perineal resection (APR) which has the impact of poor patient quality of life. With the introduction of the concept of total mesorectal excision (TME) and stapler technology, sphincter saving surgery (SSS) with its better local control and functional status is a better choice than APR. We tried to evaluate the operative safety, long-term oncologic and functional outcomes of SSS in rectal carcinoma.

Patients and methods: Between October 2008 and October 2012, patients with rectal carcinoma who presented electively to Sohag University Hospital underwent SSS based on sharp mesorectal excision in the form of anterior resection, low anterior resection and intersphincteric resection were evaluated. Patients were followed up for four years.

Results: A total of 60 patients underwent SSS, regarding operative complications; there were 2 ureteric injuries and one bladder injury. Postoperatively, anastomotic leakage occurred in $6.7 \%$ of cases. Local recurrence and distant metastases were detected in $8.3 \% 13.3 \%$ respectively. During follow-up, disease-free survival rate was $66.9 \%$, overall survival rate was 93\%, 22\% of patients had a degree of incontinence. $21.66 \%$ had temporary bladder dysfunction. Sexual dysfunction became evident in $30 \%$ of male patients.

Conclusion: SSS with TME provides a better alternative to APR in rectal carcinoma when feasible.

Key words: Sphincter saving surgery, total mesorectal excision, stapler.

\section{Introduction:}

Rectal cancer constitutes $5 \%$ of malignant tumors, and ranks as the fifth most common cancer in adults. ${ }^{1}$ It is curable when localized to the bowel, radical resection makes cure in $50 \%$ of cases. ${ }^{2}$

Preservation of anal sphincter, bladder, and sexual function with maintenance or improvement in quality of life besides local control and long-term survival are the main goals while managing rectal carcinoma. ${ }^{3}$

APR is now considered unnecessary in most patients with rectal cancer and more patients can be treated with SSS due to the increased understanding of the spread of the disease. Distal mural spread of the disease was shown to be rarely more than $2 \mathrm{~cm},{ }^{4}$ this allowed the increased use of SSS. Also the advances of mechanical stapling devices and the development of the double stapling technique made anastomoses at the distal rectum or the anal canal possible and safe. ${ }^{5}$

The recognition of TME for colorectal cancer surgery [with careful dissection of the avascular plane between the mesorectum and parietal fascia, the envelope of the mesorectum (which encompasses tumor cells) is kept intact, thereby preventing the dissemination of cancerous cells] is of significant importance. ${ }^{6}$ TME has improved the local control with/ or without the use of neo-adjuvant radiotherapy, with reduced recurrence rate from $30 \%$ down to less than $10 \%$ thus improving the overall survival. ${ }^{7,8}$ 
Most patients have tumors confined to the rectum and mesorectum and may be cured by TME based surgery. ${ }^{9}$ However, $10-15 \%$ of patients have locally more advanced tumors, i.e. tumors which are fixed to adjacent structures within the pelvis ${ }^{10}$ and those with a local recurrence, multidisciplinary treatment strategies are needed. ${ }^{9}$

Sphincter saving procedures can be performed to all patients with rectal carcinoma regardless of the site of the lesion so long the distal and lateral margins are clear. ${ }^{11}$

\section{Aim of the work:}

The purpose of this study was to evaluate the outcome of SSS in management of rectal carcinoma.

\section{Patients and methods:}

This study was conducted prospectively over patients who had non-fixed rectal carcinoma and presented electively from October 2008 to October 2012, at Sohag University Hospital, admitted through the outpatient clinic.

Patients were included in the study if they had a well functioning anal sphincters and the tumor was as low as $2 \mathrm{~cm}$ above the dentate line.

Patients were excluded if their tumors infiltrated the anal sphincter, women requiring posterior vaginectomy for adequate tumor clearance, those who received adjuvant therapy for a previous pelvic cancer, and resection for recurrent disease.

All patients had medical history, clinical examination, digital examination, endorectal ultrasonography and colonoscopy with biopsy. Tumors were divided into; low, middle, or high rectal tumors if their lowest edge were 0 to $5 \mathrm{~cm}, 5.1$ to $10 \mathrm{~cm}$, and 10.1 $\mathrm{cm}$ to $15 \mathrm{~cm}$ from the anal verge respectively.

All patients underwent abdomino-pelvic computed tomography (CT), magnetic resonance imaging and cystoscopy in patients with urinary symptoms. Laboratory investigations included serum carcinoembryonic antigen (CEA) and routine tests for physical fitness. All patients underwent routine mechanical and chemical preparation.
Data collected were patients' demographics, co-morbidities, operative details, operative morbidity and mortality, histological results, short and long-term outcomes.

\section{Surgical techniques:}

Surgical management was performed by SSS including anterior resection for highrectal tumors, low anterior resection for midrectal tumors and inter-sphincteric resection for low-rectal tumors. All patients underwent resection using a sharp perimesorectal excision technique. ${ }^{12}$ In all cases a trial was paid to preserve the pelvic autonomic nerve trunks medial to the parietal fascia. ${ }^{13}$

Restoration of gut continuity after a thorough irrigation of the pelvic cavity and irrigation of the rectal stump with povidone iodine was accomplished by double-stapling; transverse stapler, circular stapler of the appropriate size (Ethicon Endosurgery ${ }^{\circledR}$ USA), or hand sewn colorectal anastomosis.

A transanal coloanal anastomosis was performed when the transverse stapler could not be applied with adequate margin below the tumor. After full abdominal mobilization of the rectum, the surgeon completed the excision transanally at the dentate line. A hand sewn interrupted single layer anastomosis was performed at the dentate line. Our distal resection margin (DRM) was $1 \mathrm{~cm}$ for T1-2 lesions and $2 \mathrm{~cm}$ for T3-4 tumors. ${ }^{14}$ Intersphincteric resection (ISR) was performed in a low rectal cancer (tumor located $<2 \mathrm{~cm}$ from the anal ring, T12 , not infiltrating the external anal sphincter and with favorable pathology) after pelvic dissection from the abdominal approach with division of the full thickness of the internal sphincter transanally, 1 to $2 \mathrm{~cm}$ distal from the tumor, or removal of the upper one-half of the internal anal sphincter for tumors located between 3 and $5 \mathrm{~cm}$ from the anal verge (partial ISR). A diversion stoma was created in case of technical difficulty, a positive leakage test, incomplete doughnuts, or a very low anastomosis within $3 \mathrm{~cm}$ from the anal verge.

The resected tumors were evaluated 
macroscopically for tumor site, size, depth of invasion and distance from proximal and distal surgical resection margins. The perirectal lymph nodes were carefully dissected counted and sampled for assessment of metastasis. The histological tumor type, grade, depth of invasion (T-stage), lymph node deposits (N-stage) were evaluated microscopically.

Patients were followed up every 3 months during the first 2 years and then every 6 months for the further two years, average follow-up 20 months. Follow-up included history, physical examination, and serum CEA. Digital rectal examination was performed to detect any anastomotic stricture or local recurrence. If recurrence was suspected, endoscopic examination and CT scan were performed to determine whether salvage surgery could be performed. Continence was assessed by Kirwan-Fazio classification, ${ }^{15}$ patients with stoma were assessed after stoma closure.

Adjuvant radiation therapy was not routinely given to patients with stage II or stage III. Postoperative chemo-radiation was given when there is doubt of local clearance. Chemotherapy based on 5-fluorouracil was prescribed to patients younger than 75 years with TNM stage II or stage III disease.

\section{Statistical analysis:}

The commercially available statistical software (IBM-SPSS version 19.0 for Windows; IBM Inc) was used for data analysis. The frequencies of a categorical observation among different groups was compared by Chi-Square Test and Fisher`s Exact Test and the correlation between categorical variables and other continuous variables was by Spearman`s rho Test. Kaplan Meier Survival analysis was used to calculate the recurrence rate and to estimate the Log-Rank among different groups. The association of different clinical and operative factors and risk of recurrence of the disease was evaluated by Binary Logistic regression analysis. The cut-off for significance of all used statistical analyses was rated as $\mathrm{P}<0.05$.

\section{Results:}

This is a descriptive single arm prospective study which included 60 patients with rectal carcinoma, confirmed by histopathologic study as adenocarcinoma, who fulfilled the inclusion criteria. Of them 40 patients $(66.7 \%)$ were females and 20 patients (33.3\%) were males. Their age ranged between 16 to 72 years with a mean of $(43.82 \pm 15.43)$ and a median of 43.5 years. In our study; 9 patients (15\%) had high rectal tumor, 47 patients (78.3\%) had mid-rectal tumor and 4 patients (6.7\%) had low-rectal tumor. Operative time ranged between 90 and 240 minutes. The mean was (152 \pm 35$)$ and the median was 150 minutes.

The anastomosis was completed by stapler using a double stapling technique in 39 patients (65\%); all of them were mid-rectal cancer. Hand sewn anastomosis was used in 21 patients (35\%) of whom four (6.6\%) were low and eight (13.33\%) were middle and nine (15\%) were high rectal tumors. Thirty-seven patients (61.7\%) had no diverting stoma, four patients (6.7\%) had loop ileostomy and 19 (31.7\%) had protective transverse colostomy.

Operative complications were managed intra-operatively and postoperative complications were managed conservatively and responded well, both were summarized in Table (1).

The factors which may be responsible for the occurrence of fecal fistula were analyzed; small DRM was significantly associated with fecal fistula (Pearson Chi Square $=14.08$, $\mathrm{P}<0.01)$. None of the tumor site, method of anastomosis, type of the covering stoma, tumor grade or tumor stage had a significant relationship to fecal fistula $(\mathrm{P}=0.32,=0.65$ $=112$, and $=0.727$ respectively). Also there was no correlation between operative time and fecal fistula (Spearman's rho correlation coefficient, $\mathrm{P}=0.161$ ).

Histopathologic evaluation revealed that 24 patients (40\%) had well differentiated adenocarcinoma, 34 patients (56.7\%) had moderately differentiated adenocarcinoma and two patients (3.3\%) had poorly differentiated adenocarcinoma. DRM varied according to the site of the tumor, it ranged 
from 1-5 cm. It was $1 \mathrm{~cm}$ in seven cases, $2 \mathrm{~cm}$ in twenty-nine cases, $3 \mathrm{~cm}$ in nine cases, $4 \mathrm{~cm}$ in five cases and $5 \mathrm{~cm}$ in ten cases, resected specimens were examined histopathologically and were free. TNM staging of the tumors based on histopathologic examination of resected specimens (for $\mathrm{T}$ and $\mathrm{N}$ ), revealed that T1, T2, T3 and T4 were represented in 4 (6.7\%), 26 (43.3\%), 29 (48.3\%) and 1 (1.7\%) cases, respectively. Eighteen cases (30\%) had no lymph nodal deposits (N0), 29 cases (48.3\%) had N1 nodal stage and 13 cases (21.7\%) had N2 nodal stage. None of the patients had distant metastasis (M0). There was not any operative mortality.

During follow-up there was local recurrence in five cases $(8.3 \%), 4$ patients were mid-rectal carcinoma and 1 was lowrectal carcinoma. Both tumor site and method of anastomosis had no significant relationship to the local recurrence. Contrary to site of the tumor and type of anastomosis, there was an inverse significant relationship between the DRM and local recurrence. Regarding tumor grade; high grade tumors tend to have more local recurrence in comparison to low grade tumors, but this relationship does not reach the significance level. Although the relation of $\mathrm{T}$ stage of the primary tumor was insignificant, local recurrence of the tumor was significantly associated with higher nodal stage Table (2).

Multivariate statistical analysis was made for factors which could be related to local recurrence. These factors included tumor site, tumor grade, $\mathrm{T}$ stage, $\mathrm{N}$ stage, type of operation, method of anastomosis, DRM in addition to operative time. There was no single independent variable correlated with local recurrence based on Binary Logistic Regression Multivariate analysis as shown in Table (3).

Distant metastasis happened in eight patients (13.3\%) of whom 5 cases had liver deposits, 2 cases had lung deposits and 1 case had multi-organ metastasis.

Disease free survival by Kaplan Meier test was $66.9 \%$ during the study period and the overall survival rate by Kaplan Meier test was 93\% Figure (1,2). There were two deaths; 1 due to multiple metastases and the other due to pulmonary metastasis.

We evaluated the relation of different disease findings to continence status. The tumor site had a significant impact; low-rectal tumors had a highly significant increased risk of incontinence. Type of anastomosis had a direct effect, according to our results stapler completed anastomosis significantly had less risk of incontinence compared to hand sewn anastomosis. Additionally smaller DRM was more likely to be associated with disturbed postoperative anal sphincteric function. In the same respect, $\mathrm{T}$ stage of the tumors and overall stage had no correlation Table $(4,5)$.

There were temporary bladder dysfunction ( $<3$ months) in association with SSS in 13 patients (21.7\%) and were managed conservatively by Foley's catheter and one patient had permanent bladder dysfunction (>3 months) which proved to be neurogenic bladder. In the respect of sexual function, of 20 male patients who had rectal resection, 6 patients (30\%) had sexual dysfunction, 2 of them had erection problems and the other 4 had ejaculation problems.

\section{Discussion:}

The ideal treatment of rectal cancer should preserve the anal sphincter with low morbidity and mortality and favorable oncologic outcomes. Following the introduction of TME by Heald and the development of staplers, SSS became a better alternative to APR. ${ }^{16}$ In the last years, anterior resection with TME excision has become the optimal treatment of rectal cancer.

Still the tumor level is an important factor for the type of the adopted surgery, a DRM of $2 \mathrm{~cm}$ is sufficient for a SSS which wouldn't affect the survival or local recurrence in patients with rectal cancers. ${ }^{17}$ In the last few years there is a developing trend to decrease the DRM to $1 \mathrm{~cm}$, as it proved to have appropriate clearance for most rectal cancers. ${ }^{18}$ In the current study, a distal margin clearance with a $2 \mathrm{~cm}$ DRM for stage I or stage II tumors was performed and we did not find any tumor beyond this margin histopathologically. Our operative time was 


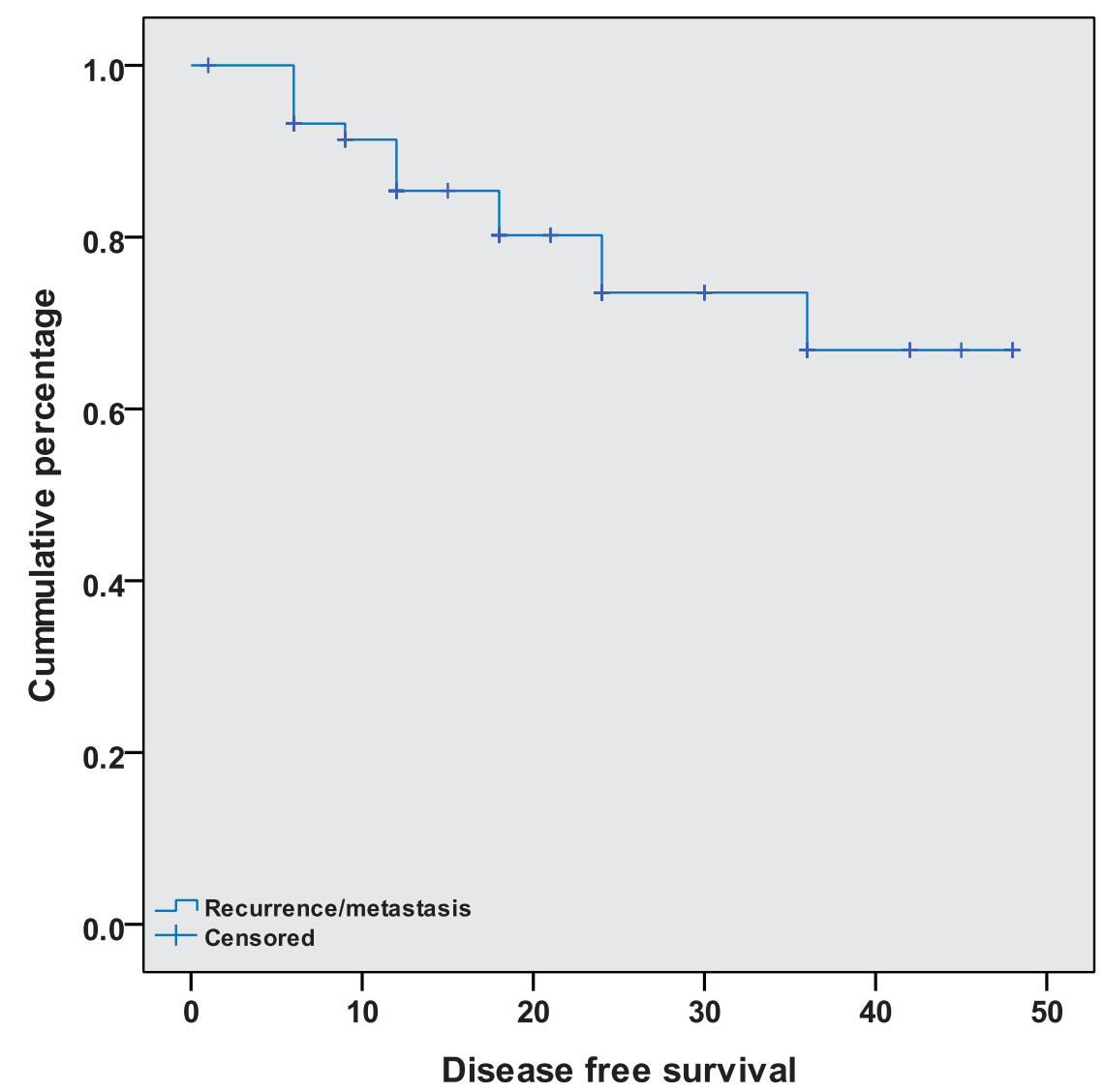

Figure (1): Disease free survival.

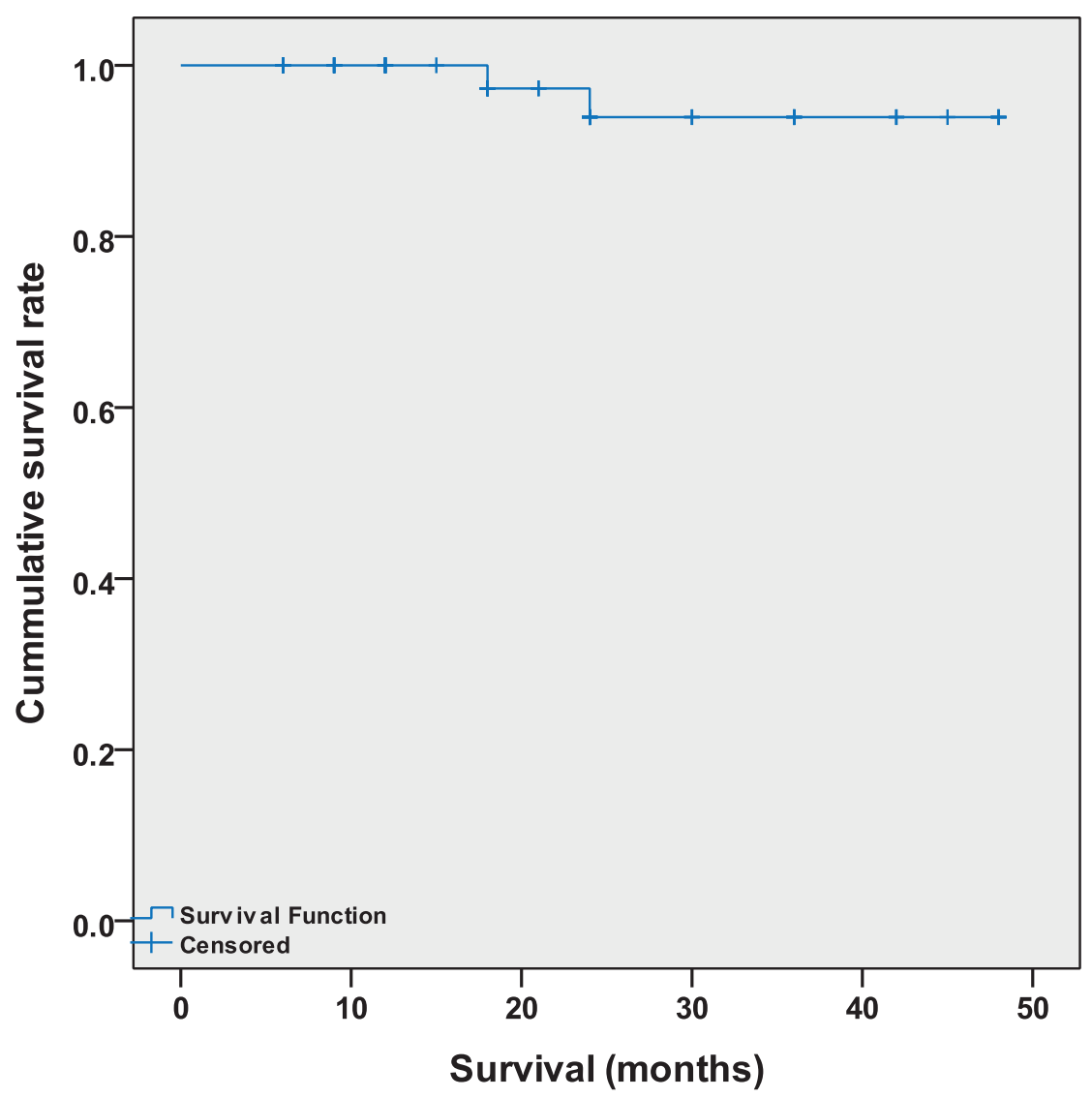

Figure (2): Overall survival. 
Table 1: Operative and postoperative complications.

\begin{tabular}{|l|l|}
\hline Complications & Number of patients (\%) \\
\hline Operative complications & \\
Ureteric injury & $2(3.3)$ \\
Bladder injury & $1(1.7)$ \\
\hline Postoperative complications & \\
Wound healing disturbances & $9(15)$ \\
Intra-abdominal infection & $2(3.3)$ \\
Fecal fistula & $4(6.7)$ \\
Stricture & $1(1.7)$ \\
\hline
\end{tabular}

Table 2: Factors affecting local recurrence.

\begin{tabular}{|c|c|c|c|c|}
\hline & $\begin{array}{c}\text { Total number } \\
\text { =60 (\%) }\end{array}$ & $\begin{array}{c}\text { Number of recurrent } \\
\text { cases }=5(\%)\end{array}$ & $\begin{array}{c}\text { Chi } \\
\text { square }\end{array}$ & P value \\
\hline $\begin{array}{l}\text { Tumor site } \\
\text { Mid-rectal } \\
\text { Low-rectal }\end{array}$ & $\begin{array}{l}47(78.3) \\
4(6.7)\end{array}$ & $\begin{array}{l}4(80) \\
1(20)\end{array}$ & 2.275 & 0.32 \\
\hline $\begin{array}{l}\text { Method of anastomosis } \\
\text { Stapler } \\
\text { Hand sewn }\end{array}$ & $\begin{array}{l}39(65) \\
21(35)\end{array}$ & $\begin{array}{l}1(20) \\
4(80)\end{array}$ & 0.539 & 0.46 \\
\hline $\begin{array}{l}\text { Distal resection margin } \\
1 \mathrm{~cm} \text { distal margin } \\
2 \mathrm{~cm} \text { distal margin } \\
3 \mathrm{~cm} \text { distal margin } \\
4 \mathrm{~cm} \text { distal margin } \\
5 \mathrm{~cm}\end{array}$ & $\begin{array}{l}7(11.7) \\
29(48.3) \\
9(15) \\
5(8.3) \\
10(16.7)\end{array}$ & $\begin{array}{l}3(60) \\
1(20) \\
1(20) \\
0(0) \\
0(0)\end{array}$ & 13.32 & $<0.05$ \\
\hline $\begin{array}{l}\text { Tumor grade } \\
\text { Poorly differentiated (grade III) } \\
\text { Moderately differentiated (grade II) } \\
\text { Well-differentiated (Grade I) }\end{array}$ & \begin{tabular}{|l}
$2(3.3)$ \\
$34(56.7)$ \\
$24(40)$ \\
\end{tabular} & $\begin{array}{l}1(20) \\
3(60) \\
1(20) \\
\end{array}$ & 5.1 & 0.078 \\
\hline $\begin{array}{l}\text { T stage of the primary tumor } \\
\text { T1 } \\
\text { T2 } \\
\text { T3 } \\
\text { T4 }\end{array}$ & $\begin{array}{l}4(6.7) \\
26(43.3) \\
29(48.3) \\
1(1.7)\end{array}$ & $\begin{array}{l}0(0) \\
2(40) \\
3(60) \\
0(0)\end{array}$ & 0.622 & 0.89 \\
\hline $\begin{array}{l}\text { Nodal stage } \\
\text { N0 } \\
\text { N1 } \\
\text { N2 }\end{array}$ & $\begin{array}{l}18(30) \\
29(48.3) \\
13(21.7) \\
\end{array}$ & $\begin{array}{l}2(60) \\
0 \\
3(40) \\
\end{array}$ & 6.52 & $<0.05$ \\
\hline $\begin{array}{l}\text { Overall stage } \\
\text { Stage I } \\
\text { Stage II } \\
\text { Stage III } \\
\text { Stage IV }\end{array}$ & $\begin{array}{l}7(11.7) \\
11(18.3) \\
42(70) \\
0(0)\end{array}$ & $\begin{array}{l}0 \\
2(40) \\
3(60) \\
0\end{array}$ & 2.11 & 0.348 \\
\hline
\end{tabular}

* Factors with bold letters were significant.

* Values in parentheses are percentages. 
Table 3: Multivariate analysis for risk factor of local recurrence.

\begin{tabular}{|l|l|}
\hline & P value \\
\hline Tumor site & 0.998 \\
\hline Tumor grade & 0.728 \\
\hline Type of anastomosis & 0.998 \\
\hline Operative time & 0.149 \\
\hline Type of stoma & 0.290 \\
\hline Distal resection margin & 0.122 \\
\hline T stage of primary tumor & 0.833 \\
\hline N stage & 0.250 \\
\hline Constant value & 0.996 \\
\hline
\end{tabular}

Table 4: The relation of different disease findings to the continence status.

\begin{tabular}{|c|c|c|c|c|c|c|}
\hline Disease findings & No & $\begin{array}{c}\text { Perfect bowel } \\
\text { function (\%) }\end{array}$ & $\begin{array}{l}\text { Incontinence } \\
\text { for flatus }\end{array}$ & $\begin{array}{l}\text { Minor } \\
\text { soiling }\end{array}$ & Chi-square & $P$ value \\
\hline $\begin{array}{l}\text { The tumor site } \\
\text { High, } \\
\text { Mid } \\
\text { Low }\end{array}$ & $\begin{array}{l}9 \\
47 \\
4 \\
\end{array}$ & $\begin{array}{l}9(100) \\
36(76.6) \\
2(50) \\
\end{array}$ & $\begin{array}{l}0(0) \\
10(21.3) \\
0(0) \\
\end{array}$ & \begin{tabular}{|l|}
$0(0)$ \\
$1(2.1)$ \\
$2(50)$ \\
\end{tabular} & 21.16 & $<0.0001$ \\
\hline $\begin{array}{l}\text { Type of } \\
\text { anastomosis } \\
\text { Stapler } \\
\text { Hand sewn }\end{array}$ & $\begin{array}{l}39 \\
21 \\
\end{array}$ & $\begin{array}{l}32(82 \%) \\
15(71.4 \%) \\
\end{array}$ & $\begin{array}{l}6(15.4) \\
4(19.1) \\
\end{array}$ & $\begin{array}{l}1(2.6) \\
2(9.5)\end{array}$ & 5.88 & 0.05 \\
\hline $\begin{array}{l}\text { Distal resection } \\
\text { margin } \\
1 \mathrm{~cm} \\
2 \mathrm{~cm} \\
3 \mathrm{~cm} \\
4 \mathrm{~cm} \\
5 \mathrm{~cm}\end{array}$ & $\begin{array}{l}7 \\
29 \\
9 \\
5 \\
10 \\
\end{array}$ & $\begin{array}{l}5(71) \\
21(72.4) \\
7(78) \\
4(80) \\
10(100)\end{array}$ & $\begin{array}{l}0(0) \\
7(24.1) \\
2(22) \\
1(20) \\
0(0) \\
\end{array}$ & \begin{tabular}{|l}
$2(29)$ \\
$11(3.5)$ \\
$0(0)$ \\
$0(0)$ \\
$0(0)$ \\
\end{tabular} & 13.9 & 0.085 \\
\hline $\begin{array}{l}\text { T stage } \\
\text { T1 } \\
\text { T2 } \\
\text { T3 } \\
\text { T4 }\end{array}$ & $\begin{array}{l}4 \\
26 \\
29 \\
1\end{array}$ & \begin{tabular}{|l}
$4(100)$ \\
$18(69.2)$ \\
$24(82.7)$ \\
$1(100)$ \\
\end{tabular} & \begin{tabular}{|l}
$0(0)$ \\
$5(19.2)$ \\
$5(17.3)$ \\
$0(0)$ \\
\end{tabular} & \begin{tabular}{|l}
$0(0)$ \\
$3(11.6)$ \\
$0(0)$ \\
$0(0)$ \\
\end{tabular} & 0.636 & 0.48 \\
\hline $\begin{array}{l}\text { Overall stage } \\
\text { Stage I } \\
\text { Stage II } \\
\text { Stage III } \\
\text { Stage IV }\end{array}$ & $\begin{array}{l}7 \\
11 \\
42 \\
0\end{array}$ & $\begin{array}{l}5(71.4) \\
10(90.9) \\
32(76.2) \\
0(0)\end{array}$ & $\begin{array}{l}2(28.6) \\
1(9.1) \\
7(16.7) \\
0(0)\end{array}$ & \begin{tabular}{|l}
$0(0)$ \\
$0(0)$ \\
$3(7.1)$ \\
$0(0)$
\end{tabular} & 2.549 & 0.636 \\
\hline
\end{tabular}

* No = number.

* Factors with bold letters were significant.

in accordance with other reports, ${ }^{19}$ although it was expected that time would become longer due to the meticulous dissection of the mesorectum but the use of stapler completed anastomosis saved much time.

One of the complications after surgery 
Table 5: Continence results according to Kirwan's classification.

\begin{tabular}{|l|l|}
\hline Stage & Frequency (\%) \\
\hline I (Perfect) & $47(78.3)$ \\
\hline II (Incontinence flatus) & $10(16.7)$ \\
\hline III (Minor soiling) & $3(5.0)$ \\
\hline V (Incontinent requiring colostomy) & $0(0)$ \\
\hline
\end{tabular}

was anastomotic leak which was reported previously to vary between 11 and $18 \% .^{20}$ Our rate was $6.7 \%$ which was described by others; 2-9 \%.21 The only factor found to be significantly associated with fecal fistula was the smaller distal resection margin, this mandates protective colostomy or ileostomy in such cases.

Before introduction of the modern surgical modalities for treatment of rectal carcinoma, the achievement of radicality with APR was in expense of the patients' quality of life with a considerable recurrence rate of $30 \% .^{7,8} \mathrm{In}$ our study, SSS with TME, local recurrence happened in $8.3 \%$ which is comparable to others. ${ }^{22}$ Some may consider this recurrence rate as being low and attribute this to a claimed short term follow-up (mean $=20$ months) which reached 4 years especially that our patients did not receive neoadjuvant therapy, it is known that $80 \%$ of the local recurrences occur within the first 2 years after surgery and with neoadjuvant therapy the local recurrence rate reached $1.5 \% .^{23}$

Factors that are possibly associated with local recurrence were analyzed, of which DRM was found to have a significant inverse relationship with local recurrence, tumor with shorter surgical distal margin has been found to have a significant higher potential of local recurrence. Also local recurrence was significantly associated with higher nodal stage of rectal adenocarcinoma.

The cancer free survival doesn't differ between SSS and APR; 18 we reported a cancer-specific survival of $66.9 \%$, which is comparable with others' results. ${ }^{24}$

Our final continence results after SSS were accepted by most of our patients. Seventy eight percent of the cases had perfect postoperative bowel functions.
None of the patients had occasional major soiling or incontinence requiring colostomy. All anastomoses were end-to-end and it is well established that direct end-toend anastomosis of proximal colon to the anorectal junction results in poorer functional results in the earlier postoperative period, ${ }^{25}$ so our results are generally satisfactory. Although some encourage pouch formation, most studies showed that pouch and straight coloanal anastomosis function becomes comparable after $1-2$ years. ${ }^{26}$ According to our results low rectal tumors had a highly significant increased risk of incontinence, 2 cases $(66.7 \%)$ with minor soiling were low rectal cancer as all of these cases (lowrectal cancer) were managed by hand sewn anastomosis transanally in which there was removal of part of the internal sphincter during ISR, accordingly an element of analsphincter insufficiency occurred leading to a degree of incontinence. ${ }^{27}$ The partial loss of sphincter control disappeared spontaneously, as in most reported studies. ${ }^{28}$

Postoperative good quality of life as a requirement of the surgical outcome doesn't entail the avoidance of colostomy only, but also the avoidance of the postoperative functional disorders of the bladder and sexual organs. Although sphincter saving operations have problems of frequent bowel movement, urgency, flatulence, and need for frequent medication but they are superior to APR regarding quality of life. ${ }^{29}$

Earlier evaluations have shown that after extensive conventional resection, bladder dysfunction due to neurological complications has been reported in up to $54 \%$ of patients after surgical resection of the rectum. ${ }^{30}$ In contrast, the introduction of TME was followed by a reduction in the 
neurological complication rates to less than $5.3 \%{ }^{29}$ In this study $21.66 \%$ had temporary bladder dysfunction ( $<3$ months) and were managed conservatively by Foley's catheter. Rectal resection was associated with sexual dysfunction in up to $59 \%$ of patients. ${ }^{13}$ In our study $30 \%$ of our male patients who had rectal resection, suffered sexual dysfunction.

\section{Conclusion :}

SSS should be considered in patients with a good functioning anal sphincter mechanism and the tumor is more than $2 \mathrm{~cm}$ above the dentate line. It neither compromises operative safety nor oncologic outcomes.

\section{Reference:}

1- Ferlay J, Bray F, Pisani P, Parkin DM: GLOBOCAN 2002 Cancer Incidence, Mortality and Prevalence Worldwide. IARC Cancer Base No. 5, version 2.0 IARC Press, Lyon, 2004.

2- UICC. UICC (International Union Against Cancer): TNM classification of malignant tumours. Sobin LH, Wittekind Ch, editors. 6th ed. New York, Chichester, Weinheim, Brisbane, Singapore, Toronto:Wiley-Liss, Book, 2002.

3- Balch Gc, Mea AD, Jose G Guillem JG: Modern management of rectal cancer. World J Gasrroentrology 2006; 12: 3186-3195.

4- Williams NS, Dixon MF, Johnston D: Reappraisal of the 5 centimetre rule of distal excision for carcinoma of the rectum: A study of distal intramural spread and of patients' survival. Br J Surg 1983; 70: 150-154.

5- Griffen FD, Knight CD, Whitaker JM, Knight CD Jr: The double stapling technique for low anterior resection. Results, modifications, observations. Ann Surg 1990; 211: 745-752.

6- Ridgway PF, Darzi AW: The role of total mesorectal excision in the management of rectal cancer. Cancer Control 2003; 10: 205-211.

7- Wibe A, Moller B, Norstein J, et al: A national strategic change in treatment policy for rectal cancer e implementation of total mesorectal excision as routine treatment in Norway. A national audit. Dis Colon Rectum 2002; 45: 857-866.

8- Birgisson H, Talback M, Gunnarsson U, Pahlman L, Glimelius B: Improved survival in cancer of the colon and rectum in Sweden. Eur J Surg Oncol 2005; 31: 845-853.
9- Palmer G, Martling A, Blomqvist L, Cedermark B, Holm T: Outcome after the introduction of a multimodality treatment program for locally advanced rectal cancer. EJSO 2005; 31: 727-734.

10- Heslov SF, Frost DB: Extended resection for primary colorectal carcinoma involving adjacent organs or structures. Cancer. 1988; 62: 1637-1640.

11- Khalil EA, EL-Zohairy M, EL-Shahawy M: Sphincter sparing procedures: Is it a standard for management of low rectal cancer. Journal of the Egyptian Nat Cancer Inst. 2004; 16: 210-215.

12- Enker WE, Thaler HT, Cranor ML, Polyak $\mathrm{T}$ : Total mesorectal excision in the operative treatment of carcinoma of the rectum. $J$ Am Coll Surg. 1995; 181: 335-346.

13- Havenga K, DeRuiter MC, Enker WE, Welvaart K: Anatomical basis of autonomic nerve-preserving total mesorectal excision for rectal cancer. $\mathrm{Br} J$ Surg. 1996; 83: 384-388.

14- Nelson H, Petrelli N, Carlin A, Couture J, Fleshman J, Guillem J, Miedema B, Ota D, Sargent D: Guidelines 2000 for colon and rectal cancer surgery. $J$ Natl Cancer Inst. 2001; 93: 583-596.

15- Kirwan WO, Rupert B, Turnbull B, Fazio VW, Weakley FL: Pull through operation with delayed anastomosis for rectal cancer. Br J Surg 1978; 65: 695-699.

16- Heald RI, Moran BL Ryall RD, Sexton R, MacFarlane JK: Rectal cancer: The Basingstoke experience of total mesorectal excision, 1978-1997. Arch Surg 1998; 133 : 894-899.

17- Shirouza K, Isomoto H, Kakegawa T: Distal spread of rectal cancer and optimal margin of resection for sphincter-preserving surgery. Cancer 1995; 76: 388-392.

18- Tohru N, Hiroshi I, Terumitsu S, Takashi T: Survival and recurrence after a sphinctersaving resection and abdominoperineal resection. Surg Today 2004; 34: 32-39.

19- Nissan A, et al: Abdominoperineal resection for rectal cancer at a speciality center. Dis Colon Rectum 2001; 44: 27-35.

20- Mannaerts GHH, et al: Urologic and sexual morbidity following multimodality treatment for locally advanced primary and locally recurrent rectal cancer. EJSO 2001; 27: 265-272.

21- Maas CP, Moriya Y, Steup WH, Klein Kranenbarg E, van de Velde CJ: A prospective study on radical and nerve-preserving 
surgery for rectal cancer in the Netherlands. Eur J Surg Oncol 2000; 26: 751-757.

22- Tocchi A, Mazzoni G, Lepre L: Total mesorectal excision and low rectal anastomosis for the treatment of rectal cancer and prevention of pelvic recurrences. Arch Surg 2001; 136: 216-220.

23- Ulrich A, Jan Schmidt J, Weitz J, Büchler MW: Total Mesorectal Excision: The Heidelberg results after TME. Recent Results in Cancer Research 2005; 165: 112-119.

24- Martling AL, Holm T, Rutqvist LE, Moran BJ, Heald RJ, Cedemark B: Effect of a surgical training programme on outcome of rectal cancer in the County of Stockholm. Stockholm Colorectal Cancer Study Group, Basingstoke Bowel Cancer Research Project. Lancet 2000; 356: 93-96.

25- Lazorthes F, Chiotasso P, Gamagami RA, Istvan G, Chevreau P: Late clinical outcome in a randomized prospective comparison of colonic J pouch and straight coloanal anastomosis. Br J Surg 1997; 84: 1449-1451.

26- Ho YH, Seow-Choen F, Tan M: Colonic
J-pouch function at six months versus straight coloanal anastomosis at two years: randomized controlled trial. World J Surg 2001; 25: 876-81.

27- Bretagnol F, Rullier E, Laurent C, Zerbib F, Gontier R, Saric J: Comparison of functional results and quality of life between intersphincteric resection and conventional coloanal anastomosis for low rectal cancer. Dis Colon Rectum 2004; 47: 832-838.

28- Cade D, Gallagher P, Schofield PF, et al: Complications of anterior resection of the rectum using the EEA stapling device. $\mathrm{Br} J$ Surg 1981; 68: 339-340.

29- Di Betta E, D'Hoore A, Filez L, et al: Sphincter saving rectum resection is the standard procedure for low rectal cancer. Int J Colorectal Dis 2003; 18: 463-469.

30- Quah HM, Jayne DG, Eu KW, Seow-Choen F: Bladder and sexual dysfunction following laparoscopically assisted and conventional open mesorectal resection for cancer. $\mathrm{Br} \mathrm{J}$ Surg 2002; 89: 1551-1556. 